\title{
Status of Serum Gamma Glutamyl Transpeptidase and Serum Homocysteine in Young Adults with Essential Hypertension
}

\author{
Aaradhana Jatwa ${ }^{1 *}$, Sarla Mahawar ${ }^{2}$, Deepa Thadani ${ }^{3}$, GG Kaushik ${ }^{4}$, Y Ramananda Singh ${ }^{5}$, JS Broka ${ }^{6}$ \\ ${ }^{1} \mathrm{MSc}$ (Medical), ${ }^{2}$ Associate Professor, ${ }^{3}$ Professor, ${ }^{4}$ Professor \& Head, ${ }^{5} \mathrm{MD}$, Department of Biochemistry, \\ ${ }^{6}$ Senior Professor, Department of Community Medicine, JLN Medical College, Ajmer, Rajasthan, INDIA.
}

\begin{abstract}
Background: Hypertension is recognized as the most common cause of cardiovascular disorder and a leading cause of morbidity and mortality in both developed and developing countries. Gamma-glutamyl transpeptidase is serum transferase enzyme synthesised by liver. It is commonly used in clinical practice to monitor liver function, hepato-biliary disorders and as a marker of alcohol intake. It has been proposed that gamma glutamyl transpeptidase is a potent preclinical marker of atherosclerosis. Hyperhomocysteinemia (HHcy) has been regarded as a new risk factor related to hypertension. Our study was aimed to find out the status of serum gamma glutamyl transpeptidase and homocysteine in hypertensive and normotensive subjects \& Correlation of serum GGT with serum homocysteine in hypertensive subjects. Materials and methods: The present study was conducted on 100 patients with essential hypertension who attended the medical OPD of Jawahar Lal Nehru Medical College and Associated Group of Hospital, Ajmer. The results of patients were compared with 50 normotensive subjects. Anthropometric parameters and biochemical estimation were performed after taking approval from Ethical Committee. The Serum GGT was measured by colorimetric kinetic assay and Serum Homocysteine was measured by ELISA technique.

Results: The mean serum level of GGT was elevated in hypertensive subjects as compared to normotensive subjects (controls) and was statistically significant $(P<0.001)$. The mean serum level of Homocysteine was elevated in hypertensive subjects as compared to normotensive subjects and was highly significant $(P<0.0001)$. The present study has also shown a positive correlation $(r=0.74)$ between serum GGT
\end{abstract}

\section{INTRODUCTION}

Hypertension is defined as blood pressure of equal to or greater than $140 / 90 \mathrm{mmHg}$ has been recognized as the most common cause of cardiovascular disorder and a leading cause of morbidity and mortality in both developed and developing countries. ${ }^{1-3}$ Essential hypertension has been appropriately called the silent killer because it is usually asymptomatic and undetected. Uncontrolled hypertension can cause damage to all organs of body. ${ }^{4}$ Essential hypertension is increasing rapidly among young generation due to changes in dietary habits and lifestyle modifications. ${ }^{5}$ Premature death in young adults is mainly due to cardiovascular diseases. Therefore it is very essential to diagnose and treat hypertension as early as possible. ${ }^{6}$

Recent research has revealed that GGT is a pro inflammatory marker involved in atherosclerosis leading to Hypertension. GGT is an important enzyme which maintains the steady state
\& serum homocysteine in hypertensive subjects

Conclusion: The present study shows that the level of both, serum GGT and serum homocysteine is raised in young adult patients with essential hypertension and has also shown a positive correlation between serum GGT \& serum homocysteine in these subjects. Thus the elevated GGT and Homocysteine in young adults may contribute to their susceptibility to hypertension and provide an additional evidence of novel role of GGT and Homocysteine in cardiovascular risk evaluation. This study was limited and needs to be further worked upon.

Keywords: Homocysteine (Hcy), Hypertension (HTN), Hyperhomocysteinemia (HHcy), Serum Y-glutamyl transpeptidase, Serum y-glutamyl transferase (GGT).

\section{*Correspondence to:}

Aaradhana Jatwa, MSc (Medical), Department of Biochemistry, JLN Medical College, Ajmer, Rajasthan, INDIA

Email: sisodia.ayurveda @gmail.com

\section{Article History:}

Received: 08-04-2016, Revised: 18-04-2016, Accepted: 23-04-2016

\begin{tabular}{|l|c|}
\hline \multicolumn{2}{|c|}{ Access this article online } \\
\hline Website: & Quick Response code \\
www.ijmrp.com & \\
\hline DOI: & \\
10.21276/ijmrp.2016.2.3.028 & \\
\hline
\end{tabular}

concentration of glutathione both inside cells and the extracellular fluids. GGT is a glycoprotein consisting of two polypeptide chains. ${ }^{7,8}$ Gamma-glutamyl transpeptidase, initially used as an indicator of liver function is now found to be elevated in other metabolic disorders like non-insulin dependent diabetes mellitus, Hypertension etc. ${ }^{9}$

Glutathione is a tripeptide, composed of Glutamic acid, Glycine and Cysteine.10,11 The main function of GGT is to degrade glutathione to form a dipeptide which act as a reducing agent and forms free radicals. ${ }^{12}$ These free radicals oxidise LDL and forms a plaque in endothelial lining of the blood vessels. Progressive formation of plaque results in atherosclerosis leading to hypertension and cardiovascular disease. ${ }^{13}$ The relationship between hyperhomocysteinemia and atherosclerosis was suggested by McCully (1969). ${ }^{14}$ 
Hyperhomocysteinemia is a medical condition generally defined as Serum Homocysteine level $\geq 15 \mu \mathrm{mol} / \mathrm{L}$. Hyperhomocysteinemia ( $\mathrm{HHcy}$ ) has been regarded as a new risk factor related to hypertension. ${ }^{15-18}$ Homocysteine is a sulfurcontaining amino acid and an intermediate in the methionine metabolism. It is recycled either by trans-sulfuration to cysteine or by remethylation to methionine and is mainly cleared through the kidneys. ${ }^{19,20}$

Numerous nutritional deficiencies (folate, vitamins $B_{12}$ and $B_{6}$, act as cofactors in methionine metabolism), genetic variation (mutation of methylene tetra- hydrofolate reductase enzyme.), drugs (phenytoin, carbamazepine), or diseases (renal insufficiency) affect homocysteine metabolism and influence serum homocysteine levels. ${ }^{21}$ Homocysteine contains a reactive sulfhydryl group that can react with plasma constituents and promotes oxidative damage. Hyperhomo cysteinemia, through its oxidative effects, could reduce vasodilators like nitric oxide as well as promote extracellular matrix accumulation and smooth muscle cell proliferation, leading to vascular constriction and stiffness..$^{22,23}$ An elevated homocysteine level therefore induces thrombogenicity, causes procoagulant state and promotes the proliferation of smooth muscle cells. ${ }^{24}$

Epidemiological studies demonstrated that both hyperhomocysteinemia and hyper- tension were related to an increased risk of cardiovascular events. ${ }^{16,25}$ In a large epidemiological study (NHANES III) each $5 \mu \mathrm{mol} / \mathrm{L}$ increase in plasma Homocysteine levels was associated with an increase in systolic (SBP) and diastolic blood pressure (DBP) of 0.7 and 0.5 $\mathrm{mmHg}$, respectively, in men, and 1.2 and $0.7 \mathrm{mmHg}$, respectively, in women. 26

However, the effect of homocysteine lowering interventions seemed to be paradoxical in the hypertensive population. Nutritional supple- ments could lower homocysteine levels in most studies, but this was not always related to blood pressure. 27,28
Our study was aimed to find out the status of serum gamma glutamyl transpeptidase and homocysteine in hypertensive and normotensive subjects \& Correlation of serum GGT with serum homocysteine in hypertensive subjects. There is not a lot of study that shows relation between serum GGT and serum homocysteine in hypertensive subjects.

\section{MATERIALS AND METHODS}

The present study is a case control study, 100 subjects with Essential hypertension (group-2) and 50 age and sex matched healthy controls (group-1) both male and female between $30-50$ years of age were recruited from Jawahar Lal Nehru Medical College and Associated Group of Hospital, Ajmer. The present study is approved by institutional ethical committee.

\section{Exclusion criteria}

Pregnant, lactating women and patients with diabetes, liver disease and patients on drugs which might influence the serum levels of GGT and Homocystiene were excluded from the study. Height and weight were measured with the subject in light clothes without shoes, and BMI was calculated by using the formula: [BMI = weight (Kgs) /height (metre) ${ }^{2}$ ]

Blood pressure (BP) was measured by physician. Patients who were found to have Systolic Blood Pressure (SBP) higher than $140 \mathrm{mmHg}$ and/or Diastolic Blood Pressure (DBP) higher than 90 $\mathrm{mmHg}$ on three consecutive days were considered as hypertensive. ${ }^{29}$

Blood samples were collected after an overnight fast (12-14hrs) under aseptic conditions from all the study participants. All samples were centrifuged and analyzed for serum GGT and Serum Homocysteine. The Serum GGT was measured by colorimetric kinetic assay and serum Homocysteine was measured by ELISA technique.

Statistical analysis: All data were analysed by SPSS-13 version. $P<0.01$ were considered as significant.

Table 1: Anthropometric Parameters of Normotensive v/s Hypertensive Subjects

\begin{tabular}{lccc}
\hline PARAMETERS & $\begin{array}{c}\text { NORMOTENSIVE } \\
\text { SUBJECTS }\end{array}$ & $\begin{array}{c}\text { HYPERTENSIVE } \\
\text { SUBJECTS }\end{array}$ & P VALUE \\
& $\mathbf{n}=\mathbf{5 0}$ & $\mathbf{n = 1 0 0}$ & \\
\hline Age $(\mathbf{y r s})$ & $39.84 \pm 6.04$ & $42.53 \pm 5.49$ & $>0.005$ \\
Height $(\mathbf{c m})$ & $156.08 \pm 7.19$ & $150.18 \pm 5.4$ & $<0.001$ \\
Weight $(\mathbf{k g})$ & $60.16 \pm 10.19$ & $67.72 \pm 8.17$ & $<0.001$ \\
BMl $\left(\mathbf{K g} / \mathrm{m}^{2}\right)$ & $21.75 \pm 2.6$ & $26.6 \pm 2.9$ & $<0.001$ \\
\hline
\end{tabular}

Table 2: Biochemical Parameters of Normotensive v/s Hypertensive Subjects

\begin{tabular}{lccc}
\hline & NORMOTENSIVE & HYPERTENSIVE & P \\
BIOCHEMICAL PARAMETERS & SUBJECTS & SUBJECTS & VALUE \\
& $\mathbf{n}=50$ & $\mathbf{n = 1 0 0}$ & \\
\hline GGT $(\mathrm{U} / \mathrm{L})$ & $34.5 \pm 8.4$ & $53.39 \pm 16.09$ & $<0.001$ \\
SERUM HOMOCYSTEINE $(\mu \mathrm{mol} / \mathrm{l})$ & $10.06 \pm 2.9$ & $18.97 \pm 4.5$ & $<0.0001$ \\
\hline
\end{tabular}

\section{RESULTS}

A total of 150 subjects were studied. The results are summarized in Tables and Figures. The Table-1, Figure-1 shows the Mean $\pm S D$ of age, weight, height and body mass index of the subjects. The Table-2, Figure-2 shows the Mean \pm SD of serum GGT $(53.58 \pm 16.09 \mathrm{v} / \mathrm{s} 34.5 \pm 8.4) \mathrm{U} / \mathrm{L}$ in hypertensive subjects compared to normotensive subjects (controls) was significantly
$(P<0.001)$ raised and the Mean $\pm S D$ of Serum Homocysteine $(18.97 \pm 4.5 \mathrm{v} / \mathrm{s} \quad 10.06 \pm 2.9) \mu \mathrm{mol} / / \mathrm{l}$ in hypertensive subjects compared to normotensive subjects was highly significant $(P<0.0001)$. Figure-3 shows positive correlation $(r=0.74)$ between serum GGT and serum Homocysteine levels in Hypertensive subjects. 
Aaradhana Jatwa et al. Serum GGT and Serum Homocysteine in Young Adults with Essential Hypertension

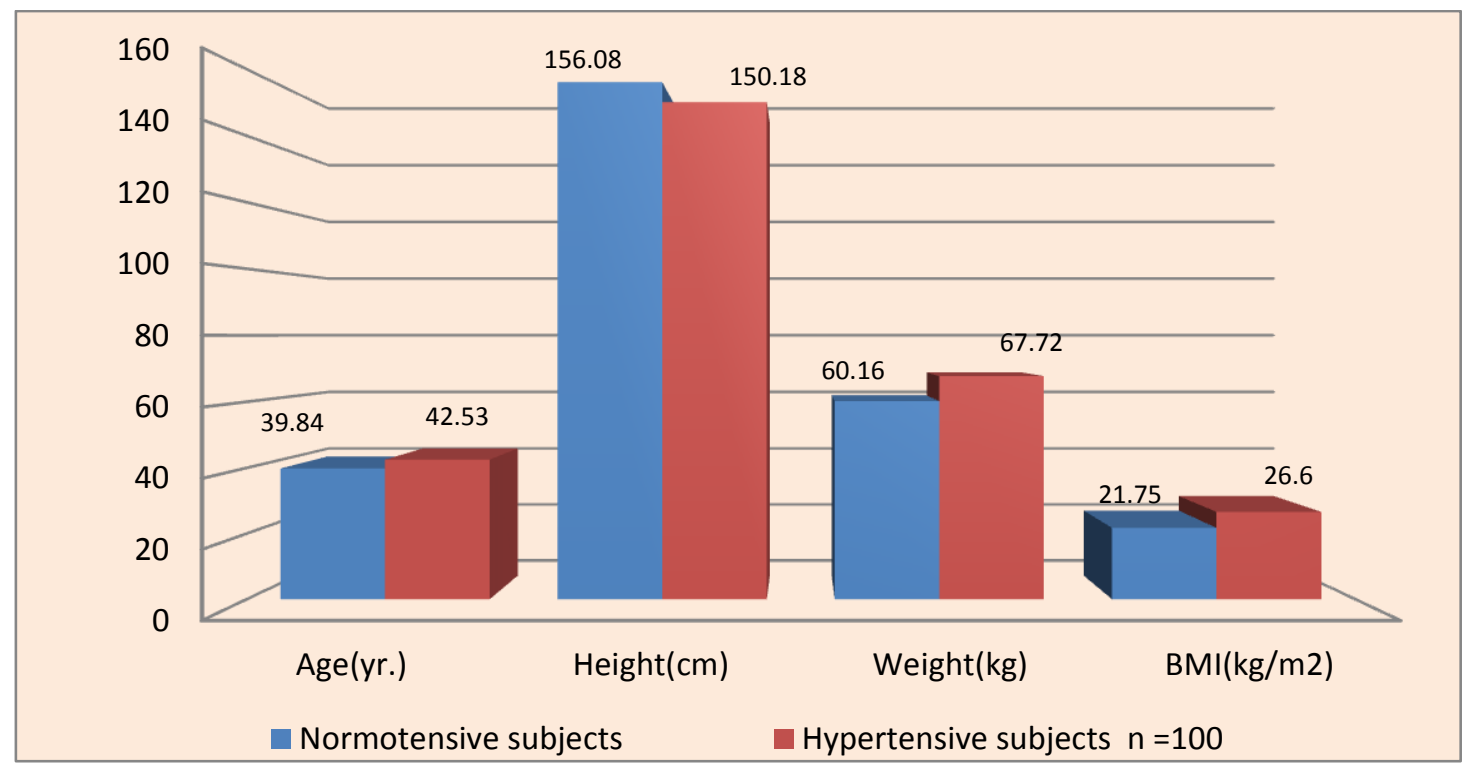

Fig 1: Comparision of Anthropometric Parameters of Normotensive v/s Hypertensive Subjects

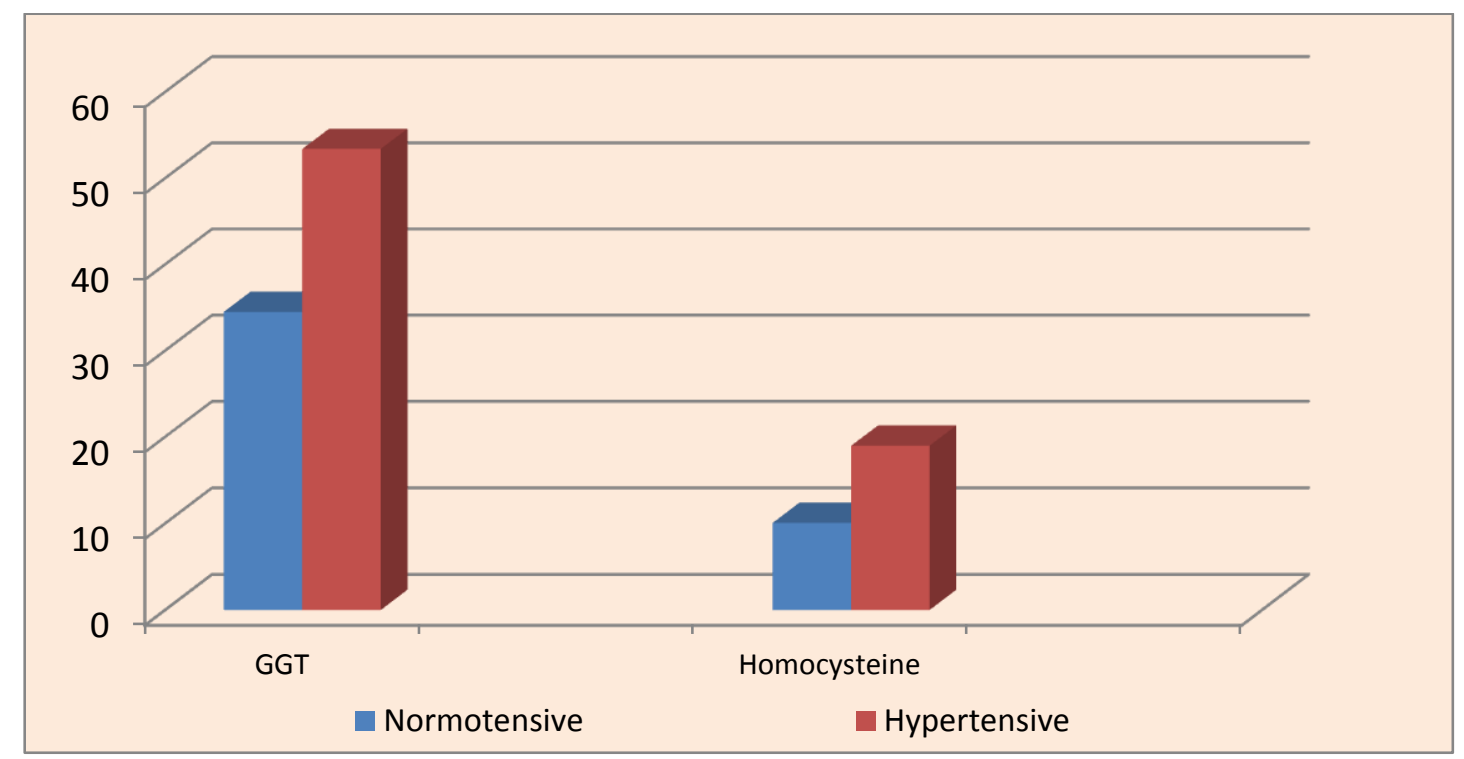

Fig 2: Comparision of Biochemical Parameters of Normotensive v/s Hypertensive Subjects

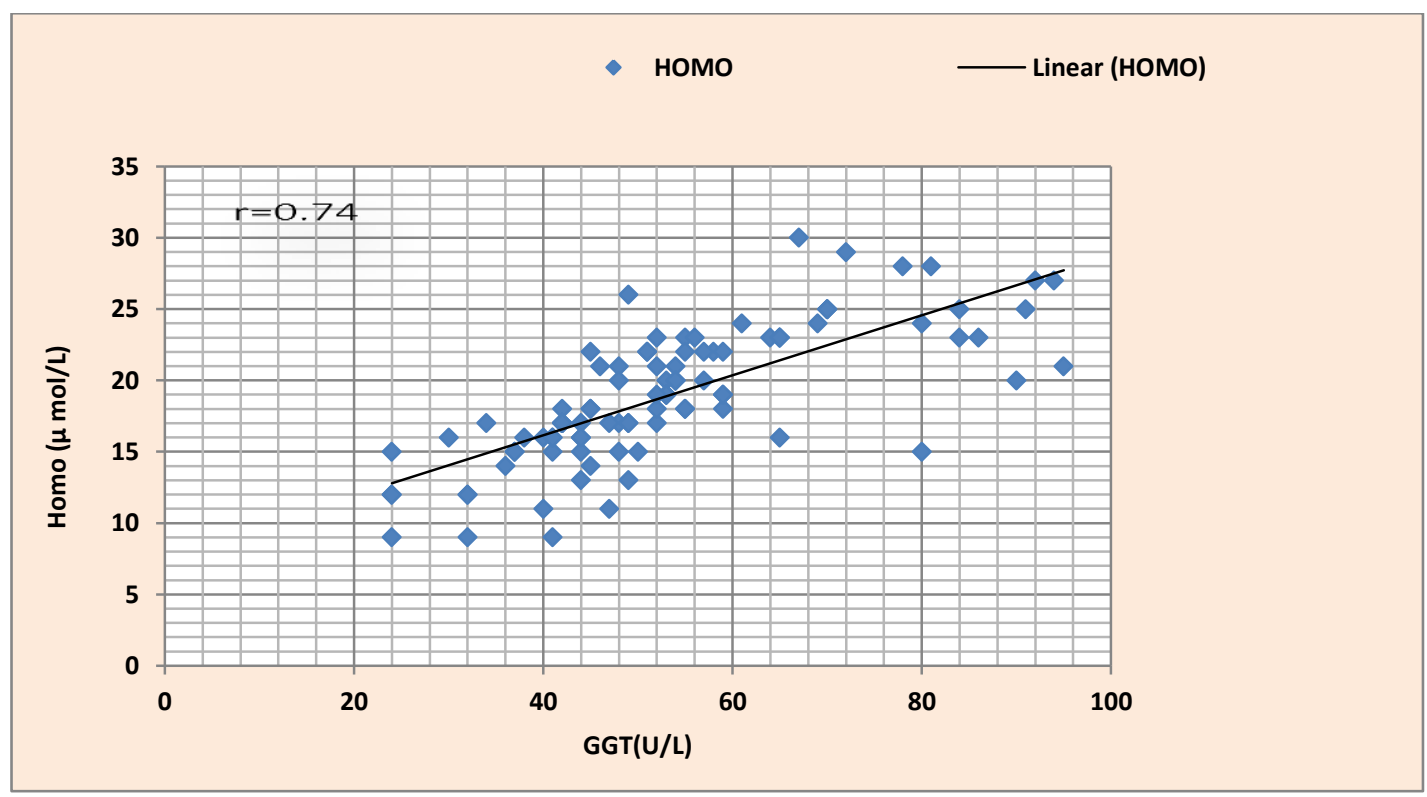

Fig 3: Correlation of Serum GGT with Serum Homocysteine in Hypertensive Subjects. $(n=100)$ 


\section{DISCUSSION}

Elevated blood pressure is a significant strong and independent risk factor for coronary artery disease both in men and women. In the present study we have observed that the level of serum GGT was elevated in hypertensive subjects as compared to the normotensive subjects. It is in concordance with the previous studies which also state that the serum GGT was elevated in hypertensive subjects [29-33]. Our finding are in agreement with Raja Rajeshwari D et al. (2015) reported that the level of serum GGT $(70.10 \pm 25.08$ v/s $23.34 \pm 8.42)$ in hypertensive subjects was highly significant than normotensive subjects. ${ }^{33}$ In the present study we have also observed that the level of serum homocysteine was elevated in hypertensive subjects as compared to the normotensive subjects. Our finding are in agreement with Alina et al. (2008) found that the value of serum homocysteine $(18.77 \pm 1.9 \mu \mathrm{mol} / \mathrm{l})$ in hypertensive subjects was highly significant than normotensive subjects. ${ }^{34}$ Drzewoski et al. (2000) reported that elevated blood levels of homocysteine is strongly related to an increased risk for atherosclerosis and cardiovascular disease. ${ }^{35}$ Our study also shows positive association between serum GGT and serum Homocysteine levels in hypertensive subjects. Plasma GGT has been suggested as a marker of oxidative stress, a risk factor of hypertension and cardiovascular diseases. ${ }^{36,37}$ GGT is a key enzyme in the catabolism of glutathione and plays a role in the production of reactive oxygen species. HHcy causes vascular dysfunction mainly through its oxidative effects, which could reduce vasodilators like nitric oxide as well as promote extracellular matrix accumulation and smooth muscle cell proliferation, which could lead to vascular constriction and stiffness. ${ }^{22,23}$ Increase in plasma concentration of homocysteine is common in patients with stroke, peripheral vascular disease ${ }^{38}$ and coronary disease ${ }^{39}$ and confer an independent risk of atherosclerosis. ${ }^{40}$

\section{CONCLUSION}

The present study shows that the level of both, serum GGT and serum homocysteine is raised in young adult patients with essential hypertension and has also shown a positive correlation between serum GGT \& serum homocysteine in these subjects. Thus the elevated GGT and Homocysteine in young adults may contribute to their susceptibility to hypertension and provide an additional evidence of novel role of GGT and Homocysteine in cardiovascular risk evaluation. This study was limited and needs to be further worked upon.

\section{REFERENCES}

1. WHO. World Health Organization Inter- national Society of Hypertension Guideline for the management of hypertension (Guideline Sub-Committee). J Hypertens 1999; 151-183.

2. The sixth Reports of the Joint National Committee on Detection, Evaluation and Treatment of High Blood Pressure (JNC VI). Arch Intern Med 1997; 157: 2413-2446.

3. WHO. Classification of hypertension. Report of WHO Scientific Group, Technical Report Series 1978; 657: 87-95.

4. Norman M, Kaplan. Clinical hypertension: 9th Ed. Lippincott \&Wilkins, USA. 2006; 15-16.

5. Darnton-Hill, lan, C. Nishida, and W. P. T. James. A life course approach to diet, nutrition and the prevention of chronic diseases. Public health nutrition. 2004; 7 (1): 101-21.
6. Sinaiko Alan R, Hypertension in children. New England Journal of Medicine. 1996; 335(26):1968-73.

7. Polotsky,Vsevolod Y. Obstructive sleep apnea, insulin resistance, and steatohepatitis in severe obesity. American journal of respiratory and critical care medicine. 2009; 179(3): 228-34.

8. Leclercq, Isabelle A. Insulin resistance in hepatocytes and sinusoidal liver cells: mechanisms and consequences. Journal of hepatology. 2007; 47(1):142-56.

9. Whitfield, J. B. Gamma glutamyl transferase. Critical reviews in clinical laboratory sciences 2001; 38 (4): 263-55.

10. Atar, Asli I. Association between gamma glutamyl transferase and coronary artery calcification. International journal of cardiology 2013; 167(4): 1264-67.

11. Shao, $\mathrm{Na}$. Design of bis-spiropyran ligands as dipolar molecule receptors and application to in vivo glutathione fluorescent probes. Journal of the American Chemical Society 2009; 132(2);725-36.

12. Mao Yu. Serum gamma-glutamyl trans- ferase: A novel biomarker for coronary artery disease. Medical science monitor: international medical journal of experimental and clinical research. 2014;20:706

13. Libby, Peter, Paul M. Ridker, and Attilio Maseri. Inflammation and atherosclerosis. Circulation.2002; 105(9): 1135-43.

14. Mc Cully K. Vascular pathology of homocysteinemia: implications for the pathogenesis of arteriosclerosis. Am J Pathol 1969; 56: 111 28

15. Refsum H, Nurk E, Smith AD, Ueland PM, Gjesdal CG. The hordaland Homocysteine study: A community-based study of homocysteine, its determinants, and associations with disease. $J$ Nutr (2006); 136: 1731S-1740.

16. Graham IM, Daly LE, Refsum HM, Robinson K, Brattstrom LE. Plasma homocysteine as a risk factor for vascular disease. The European concerted action project. JAMA 1997; 277: 1775-1781.

17. Adachi $H$, Matsuoka H, Usui M. homocysteine and hypertension. Nihon Rinsho 200058 Suppl 2: 415-417.

18 Sutton-Tyrrell K, Bostom A, Selhub J, Zeigler-Johnson C. High homocysteine levels are independently related to isolated systolic hypertension in older adults. Circulation 1997; 96: 1745-1749.

19. Refsum H, Ueland PM, Nygard O, Vollset SE. Homocysteine and Cardiovascular disease. Annu Rev Med 1998; 49: 31-62

20. Selhub J, Miller JW. The pathogenesis of homocysteinemia: Interruption of the coordinate regulation by s-adenosylmethionine of the remethylation and transsulfuration of homo- cysteine. Am J Clin Nutr 1992;55: 131-138.

21. Welch GN, Loscalzo J. Homocysteine and atherothrombosis $\mathrm{N}$ Engl J Med 1998; 338 : $1042-1050$.

22. Ovechkin AV, Tyagi N, Sen U, Lominadze D, Steed MM. 3deazaadenosine mitigates arterial remodeling and hypertension in hyperhomocysteinemic mice. Am J Physiol Lung Cell Mol Physiol. 2006; 291: L905-911.

23. Sen U, Tyagi SC. Homocysteine and Hypertension in Diabetes: Does PPARgamma Have a Regulatory Role? PPAR Res 2010: 806538.

24. Salahuddin, Siddiqui MA, Motahir S, Shah A, Karira KA. Evaluation of serum homocysteine in patients with unstable angina, a new potential risk factor. Pak J Pharm 2001;18:17-22.

25. Hao L, Ma J, Zhu J, Stampfer MJ, Tian Y, et al. High prevalence of hyperhomo -cysteinemia in chinese adults is associated with low folate, vitamin $B_{12}$, and vitamin $B_{6}$ status. J Nutrition 2007;137: 407413.

26. Lim U, Cassano PA. Homocysteine and blood pressure in the Third National Health and Nutrition Examination Survey, 1988-1994. Am J Epidemiol 2002;156: 1105-1113. 
27. Vianna AC, Mocelin AJ, Matsuo T, Morais-Filho D. Uremic hyperhomocysteinemia: A randomized trial of folate treatment for the prevention of cardiovascular events. Hemodial Int 2007; 11: 210-216. 28. Mcmahon JA, Skeaff CM, Williams SM, Green TJ. Lowering homocysteine with $B$ vitamins has no effect on blood pressure in older adults.J Nutr 2007; 137: 1183-1187.

29. Kotani K, Shimohiro H, Adachi S, Sakane N. The association between an increased level of gamma Glutamyl transferase and systolic blood pressure in diabetic subjects. Tohoku J Exp Med. 2008; 214:321-5.

30. Shankar A, Li J. Association Between Serum Gamma-Glutamyl transferase Level and Prehypertension Among US Adults. Circ J.2007;71:1567-72.

31. Lee DS, Evans JC, Robins SJ, Wilson PW, Albano. Gamma Glutamyl transferase and metabolic syndrome, cardiovascular disease, and mortality risk: The Framingham Heart Study. Arterioscler Thromb Vasc Biol. 2007; 27: 127-33.

32. Iqbal A, Khoja A, Iftikhar $U$, Mehjabeen A comparison of the effects of Gamma Glutamyl transferase on age and obesity among normal, hypertensive and type 2 diabetics. Biomedica.2009;25:123-7.

33. Rajarajeswari, Ramalingam. Serum gamma-glutamyl transpeptidase and lipids in young adults with uncomplicated essential Hyper- tension. Int J Med Res Health Sci. 2015; 4(3): 578 581

34. Alina Atif, Muhmmad Atif Rizvi. Serum homocysteine concentration in patients with hypertention; Pak J Physiol 2008;4(1).

35. Drzewoski J, Czupryniak L, Chwatko G, Bald E. Hyperhomocysteinemia in poorly controlled type 2 diabetes patients. Diabetes Nutr Metab 2000;(13) .319-24.

36. Mason JE, Starke RD, Van Kirk JE. Gamma-glutamyl transferase: a novel cardio vascular risk biomarker. Prev Cardiol 2010;(13) 36 -41.
37. Lee DH, Gross MD, Jacobs DR Jr; Cardiovascular Risk Development in Young Adults Study. Association of serum carotenoids and tocopherols with gamma glutamyl trans- ferase: the Cardiovascular Risk Development in Young Adults (CARDIA) Study. Clin Chem 2004; (50).582-8.

38. Sesylhub J, Jacques PF, Wilson PWF, Rush D, Rosenbeg IH.Vitamin status and intake as primary determinants of homocysteinemia in an elderly population. JAMA 1993;270:2693-8.

39. Malinow MR, Duell PB, Hess DL, Anderson PH, Kruger WD, Phillipson BE. Reduction of plasma homocysteine levels by breakfast cereal fortified with folic acid in patients with coronary heart disease. N Engl J Med 1998; 338: 1009-15.

40. SatoY, Kaji M, Kondo M, Yoshida H, Satoh K,Metoki N. Hyperhomocysteinemia in Japanese patients with convalescent stage ischemic stroke: Effect of combined therapy with folic acid and methylcobalamine. J Neur Sci 2002; 202:65-8.

Source of Support: Nil. Conflict of Interest: None Declared.

Copyright: (c) the author(s) and publisher. IJMRP is an official publication of Ibn Sina Academy of Medieval Medicine \& Sciences, registered in 2001 under Indian Trusts Act, 1882.

This is an open access article distributed under the terms of the Creative Commons Attribution Non-commercial License, which permits unrestricted non-commercial use, distribution, and reproduction in any medium, provided the original work is properly cited.

Cite this article as: Aaradhana Jatwa, Sarla Mahawar, Deepa Thadani, GG Kaushik, Y Ramananda Singh, JS Broka. Status of Serum Gamma Glutamyl Transpeptidase and Serum Homocysteine in Young Adults with Essential Hypertension. Int J Med Res Prof. 2016; 2(3):131-35. 